Running head: THE ECOLOGY OF INTERACTIVE LEARNING ENVIRONMENTS

The Ecology of Interactive Learning Environments: Situating Traditional Theory Genevieve Marie Johnson, Ph.D.

School of Education

Curtin University

GPO Box U1987

Perth, Western Australia 6845

g.johnson@curtin.edu.au

Biographical Note

Dr. Genevieve Marie Johnson is an educational psychologist in the School of Education at Curtin University of Technology in Western Australia. Her research agenda includes theoretical, empirical, and practical understanding of digital technologies and human learning and development. For the details of Genevieve's professional contributions, visit her page at http://members.shaw.ca/gen.johnson/ 


\begin{abstract}
In educational discourse on human learning (i.e., the result of experience) and development (i.e., the result of maturation), there are three fundamental theoretical frameworks, -behaviourism, cognitivism, and constructivism, each of which have been applied, with varying degrees of success, in online environments. An ecological framework of human learning and development in interactive learning environments is proposed. Such an inclusive paradigm organizes the fundamental theoretical assumptions of behaviourism (i.e., automated learning), cognitivism (i.e., recall, understanding, analysis, synthesis, evaluation, creativity, problem solving), and constructivism (i.e., private and shared meaning). Based on review of the literature, behaviourism is best conceptualized as a learning theory; constructivist theoretical assumptions are best applied to cognitive development including private online experience (cognitive constructivism) and shared online experience (social constructivism). Cognitivism is a particularly relevant theoretical orientation in understanding both human learning and development in interactive learning environments.
\end{abstract}




\section{The Ecology of Interactive Learning Environments: Situating Traditional Theory}

According to Hill (2002), educational theory serves two critical functions. First, it provides a vocabulary and a conceptual framework for interpreting observations of teaching and learning. Second, it suggests solutions to improve teaching and learning under a range of circumstances including, recently, interactive online environments (Malikowski, Thompson, $\&$ Theis, 2007). Theoretically, instructional science includes focus on human learning (i.e., change in an individual as a consequence of environmental experiences) and development (i.e., change in an individual as a consequence of biological maturation). White, Collins and Frederiksen (2011) note that theory construction is the central goal of science. "where theories are coherent bodies of concepts, laws, and models, which account for a wide range of observations and enable humans to predict, control, and explain what happens as event occur” (p. 42). In educational discourse on learning and development, there are three fundamental theoretical frameworks, -- behaviourism, cognitivism, and constructivism, each of which have been applied, with varying degrees of success, in interactive learning environments.

\section{Behaviourism Applied to Interactive Learning Environments}

Behaviourism, as the term implies, focuses on observable behaviour and manipulation of environmental contingencies, particularly, positive reinforcement (Schunk, 2004). From a developmental perspective, behaviour is a function of experience and, as such, environmental associations and consequences are assumed to control developmental outcomes. From a learning perspective, curriculum is fractured into manageable tasks that can be practiced until mastery is achieved (Hill, 2002). Such a theoretical orientation lent itself to early teaching machines and practices such as mastery learning (ML), programmed instruction (PI), and computer-assisted instruction (CAI). Indeed, the instructional sequences in ML, PI, and CAI are identical; distinctive units, small steps, simultaneous corrective feedback, and 
individualized practice (Burton, Moore, \& Magliaro, 2004). Not surprisingly, the most common criticisms of behavioural approaches to instruction include lack of meaningful learning and student boredom associated repeated drill and practice (Malikowski et al., 2007). Increasingly, interactive learning environments have the capacity to overcome such limitations with the inclusion of, for example, video representation of required content (Moreno \& Valdez, 2007) and multimedia personalization (Zaidel \& Luo, 2010).

Research repeatedly confirms the value of systematic and structured approaches to learning and that such approaches are easily delivered in online environments (Sosa, Berger, Saw, \& Mary, 2011). Efendiogla and Yelken (2010) reported that computer-based PI was more effective in facilitating academic achievement in preservice teachers than was an instructional approached focused on meaningful learning. Barrow, Markman, and Rouse (2008) confirmed the superiority of CAI in secondary school algebra learning. In comparing traditional and computer-assisted remedial reading interventions, the enduring effectiveness of interactive learning environments was apparent (Saine, Lerkkanen, Ahonen, Tolvanen, \& Lyytinen, 2010). From a developmental perspective, the characteristics of children with autism spectrum disorder (e.g., desire for repetitive experiences and difficulty with social interaction) render online environments of considerable benefit (Pennington, 2010). Automation associated with specific applications of technology has the capacity to influence both learning and development (Ayhan \& Aral, 2009). Malikowski and colleagues (2007) concluded that "behaviorism is best suited for tasks that require low cognitive processing and learners with low levels of task knowledge" (p. 155).

\section{Cognitivism Applied to Interactive Learning Environments}

The inability of behaviourism to explain the development of complex human abilities such as language (Chomsky, 2006) led to cognitive views of learning (Berliner, 2006; Bransford, Brown, \& Cocking, 2000). Cognitive theories explain human learning and 
development in terms of changes in mental structures and intellectual processes involving the acquisition, organization, and utilization of knowledge (Schunk, 2004). Cognitivism assumes that learners actively construct meaning from sensory input based on past experiences (Royer, 2005). Cognitivism has been extremely influential in instructional design (Malikowski et al., 2007) and has run parallel to the public acceptance and use of interactive technologies. For example, the most common cognitive metaphor for human memory is referred to as the information processing model, a term clearly reflecting the digital revolution. In interactive learning environments, common concepts include cognitive demand (Torraco, 2002), cognitive load (Vogel-Walcutt, Gebrim, Bowers, Carper, \& Nicholson, 2011), cognitive technology tools (Suh, 2010), cognitive remediation (Vance, McNees, \& Meneses, 2009), and cognitive engagement (Scott \& Walczak, 2009), to mention but a few. Interactive learning environments support the development of complex cognitive processes including problem solving (Kim \& Hannafin, 2011). Metacognitive skills such as planning and organization are facilitated in online environments (Kramarski \& Michalsky, 2010). Indeed, cognitive-developmental theorists have long been interested in the role of tools in the development of mental processes (Luria, 1976; Vygotsky, 1978). Bruner (2005) maintained "that our minds appropriate ways of representing the world from using and relating to the codes or rules of available technology" (p. x). Johnson (2008a) reported a relationship between cognitive skills and internet use. In every case of significant differences, cognitive scores "were greater for individuals who frequently, as opposed to infrequently, used the internet, both in general and with respect to specific applications such as online communication" (p. 2103). Further, "students who reported frequently using search engines scored significantly higher on the measure of metacognition (i.e., planning) than students who infrequently used the same cultural artefact" (p. 2104). In this regard, cognitivism is a 
particularly relevant theoretical orientation in understanding both human learning (Johnson, 2008b) and development (Johnson, 2009) in interactive learning environments.

\section{Constructivism Applied to Interactive Learning Environments}

Constructivism, as the term implies, reflects the fundamental theoretical assumption that learners actively construct knowledge (Girvan \& Savage, 2010). The origin of such a conceptual framework can be traced to philosophical debate regarding the nature of reality and cognitive-developmental theorists such as Piaget and Vygotsky (Kotzee, 2010). According to this theoretical perspective, human learning and cognitive development unfold in relation to interaction with others (social constructivism; Vygotsky, 1978) and in relation to maturation and personal experience (cognitive constructivism; Piaget, 1970). That is, constructivism originated as a conceptual framework for understanding cognitive development. As children make meaning, their personal and social constructions are ideally suited to their cognitive capacities and vice versa (Luria, 1976). The utility of constructivist assumptions in formal learning environments, however, is questionable (Vogel-Walcutt et al., 2010).

From a constructivist perspective, there is no concept of error or incorrectness (Moats, 2007). Since knowledge is constructed, one construction is not inherently better or worse than another. In understanding human development, such an assumption is, not only reasonable but, in fact, supportive of development. Development unfolds in response to biological maturation and environmental experience which interact to enhance cognitive development. A child's construction of an airplane as a bird is accurate in relation to his/her existing understanding and experience (Piaget, 1970). In an instructional context, constructivists, rather than correcting and prescribing exactness, celebrate inventive and explorative uses of, for example, written language (Johnson, 2004). Constructivists are opposed to direct teaching and, instead, focus on facilitating learning with minimal teacher direction (Malikowski et al., 
2007). Although not without controversy (Gordon, 2009), constructivist approaches to instruction are generally not supported by empirical evidence of effectiveness (Kirschner, Sweller, \& Clark, 2006). Kotzee (2010) concluded that "constructivist epistemology undermines effective teaching; as such, realistic teaching practice cannot proceed from constructivist assumptions regarding the nature of knowledge" (p. 177). In comparing the relative utility of cognitive versus constructivist approaches to teaching complex skills using military command and control tasks, Vogel-Walcutt and colleagues (2010) concluded that "while contemporary researchers continue to defend the use of constructivist strategies for teaching, our research supports earlier findings that question the utility, efficiency, and impact of these strategies in applied domains" (p. 1).

The constructivist paradigm, characterized by subjective epistemological assumptions, is instructionally inclusive to the point of meaninglessness and misinterpretation. Huang, Rauch, and Liaw (2010) noted a shift in web-based learning from conventional multimedia to a more immersive and interactive virtual reality-learning environment (VRLE). They identified "constructivist learning as the pedagogical engine driving the construction of VRLE" (p. 1171), although their conclusions emphasized the core cognitive skills of problem solving and creativity. Based on case study analysis, Ruey (2010) argued for constructivistbased instructional design in online learning but, in sharp theoretical contrast, concluded that “in order to maintain high-quality learning, appropriate assessment plans and adequate facilitation must be particularly reinforced" (p. 706). Tekos and Solomonidou (2009) described an innovative approach to teaching science using information and communication technology. Their proposed constructivist learning environment included problem solving and teacher scaffolding, both associated with cognitive views of learning (Royer, 2005). In analysing online discussion, Kim and Bateman (2010) concluded that "higher-order thinking questions yielded more collaborative patterns among students than questions asking the 
knowledge at the literal level" (p. 79). While a focus on thinking skills clearly reflects a cognitive perspective, their espoused theoretical paradigm was constructivism. Indeed, the term constructivism is so popular in the literature on interactive learning environments that it has become a general terms for cooperative approaches to instruction (e.g., Zhang, Olfman, \& Firpo, 2010), project-based learning (e.g., Neo \& Neo, 2010), and active student involvement (e.g., Neely, Blowers \& Ragas, 2010), all of which originated from a cognitive paradigm.

The theoretical utility of behaviourism, cognitivism, and constructivism is not in question. The essential question remains: To what extent and in what ways can traditional theory be appropriately applied to interactive learning environments? The processes that give rise to human development (i.e., maturation) and learning (i.e., the result of experience) are of equal instructional concern and may be more easily facilitated in digital, as opposed to real, environments. Behaviourism is best conceptualized as a learning theory (Hill, 2002; Schunk, 2004). Constructivist assumptions are most reasonable understood in relation to cognitive development (Luria, 1976; Piaget, 1970; Vygotsky, 1978). Cognitivism is a particularly relevant theoretical orientation in understanding both human learning and development (Bruner, 2005; Royer, 2005; Vogel-Walcutt et al., 2011). In line with a meta-theoretical perspective (White et al., 2011), a comprehensive theoretical framework might organise the conceptual contributions of behaviourism, cognitivism, and constructivism to interactive learning environments

\section{The Ecology of Interactive Learning Environments}

An ecological model of human learning and development provides a comprehensive framework by situating the person within a system of relationships affected by multiple levels of the surrounding environment (Bronfenbrenner, 1977; Johnson \& Puplampu, 2008). Bronfenbrenner (1989) organized the contexts of human development into five nested environmental systems, with bi-directional influences within and between systems. The 
microsystem refers to immediate environments and includes home, school, and community interactions. The mesosystem is comprised of connections between immediate environments (e.g., parent-teacher interactions). The exosystem includes environmental settings that indirectly affect the developing person (e.g., the parent's workplace). The macrosystem reflects overarching social ideologies and cultural values (e.g., the rights of children). The chronosystem highlights the effect of time (e.g., life transitions) on all systems and all developmental processes. Bronfenbrenner (2005) recently proposed the bioecology, that is, the person's own biology is conceptualized as a dimension of the microsystem. The ecological model provides "a unified but highly differentiated conceptual scheme for describing and interrelating structures and processes in both the immediate and more remote environment as it shapes the course of human development" (Bronfenbrenner, 1979, p. 11).

Ecological theory (Bronfenbrenner, 1977, 1979) emerged prior to the digital revolution and the developmental impact of then available technology (e.g., television) was conceptually situated in the microsystem. Given the continuously increasing complexity and availability of digital technology, Johnson and Puplampu (2008) proposed the ecological techno-subsystem, a dimension of the microsystem which includes human interaction with both living (e.g., peers) and nonliving (e.g., hardware) elements of communication, information, and recreation digital technologies in immediate or direct environments. From an ecological perspective, the techno-subsystem mediates bidirectional interaction between the person and the microsystem. Ecological analysis of interactive learning environments reflects conceptual recognition of reciprocal influences among and within systems (Johnson, 2010). For example, in advanced nations, aspects of the learner's microsystem are affected by interactive digital technologies (e.g., online communication with peers). Parental use of the internet at work, an element of the exosystem, may indirectly affect children's home internet access. School internet portals are mesosystemic, allowing parents online access to their children's homework assignments, 
attendance records, and grades. Macro-analysis establishes the cultural value of some uses of digital technologies (e.g., learning) and the devaluation of other uses (e.g., social deviance). The role of interactive learning environments increases as a result of life transitions such as starting school and starting postsecondary education (e.g., the chronosystem).

An ecological orientation to interactive learning environments builds upon Bronfenbrenner's $(1977,1979,1989,2005)$ notion that human development is the consequence interactions in immediate settings. From an ecological perspective and as illustrated in Figure 1, the learner (i.e., bio-ecology) is conceptually situated in a series of nested systems. Developmental processes (i.e., cognitive, social, emotional, and physical) unfold in response to interaction between bio-ecology (e.g., temperament, personality, attention span, learning style) and elements of the microsystem (i.e., interactive learning environments). Development is the consequence of reciprocal exchange between interactive learning environments accessed, for example, home and school and individual biology. Learning outcomes (i.e., remembering, understanding, analysing, synthesising, applying, evaluating, and creating; Anderson \& Krathwohl, 2001) are influenced by student level of cognitive, social, emotional, and physical development. Simultaneously and in an upward spiral, learning contributes to increasing levels of individual development.

-- Insert Figure 1 here --

The inclusive and comprehensive nature of an ecological orientation permits organization of environmental influences on learning and development and, also, of theories of learning and development. As illustrated in Figure 1, behaviourism, cognitivism, and constructivism are organized within an ecological framework; each theory explains aspects of learning and development. In an automated and, thus, solitary sense, behavioural tenants support the creation and maintenance of online experiences that facilitate basic cognitive and 
behavioural processes including recall of specific fact, drill and practice, and application of discrete rules (Ayhan \& Aral, 2009; Pennington, 2010; Saine et al., 2010; Sosa et al., 2011).

Cognitivism is particularly germane to the study of cognitive development (i.e., change in mental processes and structures over time) as well as to all aspects of human learning. Such a theoretical orientation views individuals as "goal-directed agents who actively seek information" (Bransford et al., 2000, p. 10). Cognitive development and learning are dynamic processes that extend bio-ecology (i.e., innate abilities and genetic predispositions) and lay the foundation for all human learning. Cognitivism includes the fundamental processes of attention, perception, memory, problem solving, and metacognition and includes all aspects of acquiring and utilizing knowledge and skills (Schunk, 2004). The cognitive revolution created the science of instruction and continues to be, relative to behaviourism and constructivism, the most inclusive and practical theory of human learning (Royer, 2005). As illustrated in Figure 1, online experience is built upon the interactive and spiralling systems of bio-ecology, physical, social, emotional, and cognitive development, and learning. In turn, human development and learning are influenced by all forms of online experience (Johnson, 2008a, 2008b, 2010).

Interactive learning environments may be meaningfully dichotomized as private or shared. For example, the internet provides opportunities to engage in private solitary activities such as reading, playing games, accessing videos, and retrieving personal information (e.g., banking). The internet also provided unprecedented opportunities for shared social activities such as learning (Kim \& Bateman, 2010), playing (Soute, Markopoulos, \& Magielse, 2010), and working (Warren \& Fuller, 2010). Johnson and Kupla (2007) maintained that user behaviour reflects a variety of psychological motives including affiliation (e.g., social connection). Reportedly, $57 \%$ of all internet use relates to communication such as email, instant messaging, and chat (Nie, Simpser, Stepanikova, \& 
Zheng, 2005). From an ecological perspective and as illustrated in Figure 1, shared online experience influences and is influenced by private online experience which, in turn, impacts on learning and development.

Cognitive constructivism, as presented in Figure 1, is a particularly useful theoretical orientation to understanding private online experience including, for example, efficient execution of specific tasks (e.g., renew library books) to behaviour such as surfing and browsing which are often unfocused and unproductive (Johnson, 2007). Individuals often play digital games (Steinkuehler, 2009) and read e-books (Lam, Lam, Lam, \& McNaught, 2009). In such cases, however, constructions of meaning, while developmentally appropriate and restorative of equilibration, are personal and private and, therefore, not necessarily consistent with shared experiences. There is individual variation in interpretation of websites, utilization of software features, and selection and application of digital information (Johnson $\&$ Kupla, 2007). From a cognitive constructivist perspective, such variation reflects differences in individual patterns of developmental maturation and culminating online experiences.

In addition to understanding the processes of cognitive development, social constructivism, as illustrated in Figure 1, is a particularly useful theoretical orientation to understanding shared online experience. According to Vygotsky (1978), cognitive development is the consequence of social interaction with a more knowledgeable other and language is central to the development of cognitive processes. Shared online experience includes a range of communication options including multimedia, hypermedia, and Web2 applications. Bailenson and Ducheneaut (2009) demonstrated that our digital bodies change the nature of social interactions in avatar-based online communities as well as in subsequent face-to-face interactions. Shared online experiences scaffold individual interpretations of, and competencies in, interactive learning environments. Indeed, the limitations of email and the 
extent to which emoticons improve communication support the notion that individual meaning is constructed via digital interactions with others (Kato, Kato, \& Scott, 2009). Based on a sample of 2400 internet users, King (2008) reported that subcultures emerged in response to shared meanings rather than demographic variables assumed to be culturally binding (e.g., age).

Shared and private online experiences are influenced by changing technologies and changing users. In the context of an ecological framework of interactive learning environments, the chronosystem reflects both user transitions (e.g., starting school, starting university, and entering the workplace) and technical innovations (e.g., ubiquitous connectivity). A recent European Cooperation in Science and Technology brainstorming session concluded rapid and profound transformations in social organization, governance, and quality of life (Arnaldi, Boscolo, \& Stamm, 2010). "New forms of learning will be created to better respond to emerging needs ... lifelong learning will be critical; people will live longer and work longer, with a constant need to update their skills" (p. 406). Furthermore, knowledge will be organized and delivered horizontally to cover a wide range of disciplines. Education will focus primarily on the promotion of higher-order thinking skills. Learners will be intrinsically motivated as educational activities are woven into their everyday experiences "Creativity will be re-defined as a key value, and creative thinking and acting will be fostered at all levels" (p. 409). As presented in Figure 1, the chronosystem, first, recognizes individual change as a function of maturation and experience and, second, anticipates social and technological change over time which will influence interactive learning environments.

The continuous improvement of interactive learning environments is the consequence of human capabilities. As a result of increased private and shared online opportunities for cognitive and social stimulation (Johnson, 2008c), human capabilities are enhanced in interactive environments (Nickerson, 2005). Correspondingly, continuous improvements in 
theories of learning and development are the consequence of continuous improvements in human cognitive capabilities. Improved theory provides for improved opportunities to learn and grow in interactive environments. It is thus that human abilities and human environments are co-creators (Bruner, 2005). 


\section{References}

Anderson, L. W., \& Krathwohl, D. R. (2001). A taxonomy for learning, teaching, and assessing: A revision of Bloom's Taxonomy of educational objectives. Boston: Allyn and Bacon.

Arnaldi, S., Boscolo, F., \& Stamm, J. (2010). Living the digital revolution - Exploration into the futures of the European society. European Review, 18, 399-416. doi:10.1017/S106279810000098

Ayhan, A. B., \& Aral, N. (2009). Computer-assisted instruction in concept development of six-year-old children. Psychological Reports 104, 853-860.

Bailenson, J. N., \& Ducheneaut, N. (2009). The proteus effect: Implications of transformed digital self-representation on online and offline behavior. Communication Research, 36, 285-312.

Barrow, L., Markman, L., \& Rouse, C. E. (2008). Technology's edge: The educational benefits of computer-aided instruction. NBER Working Paper No. 14240. A National Bureau of Economic Research Project Report [0-226-26621-4].

Berliner, D. C. (2006). Educational psychology: Searching for essence throughout a century of influence. In P. A. Alexander \& P. H. Winne (Eds.). Handbook of educational psychology (2 ${ }^{\text {nd }}$ ed., pp. 3-42). Mahwah, NJ: Lawrence Erlbaum.

Bransford, J., Brown, A., \& Cocking, R. (Eds.) (2000). How people learn: Brain, mind, experience, and school. Washington, DC: National Academy.

Bronfenbrenner, U. (1977). Toward an experimental ecology of human development. American Psychologist, 32, 513-531.

Bronfenbrenner, U. (1979). The ecology of human development: Experiments by nature and design. Cambridge, MA: Harvard University Press. 
Bronfenbrenner, U. (1989). Ecological systems theory. Annals of Child Development, 6, 187224.

Bronfenbrenner, U. (2005). Making human beings human: Bioecological perspectives of human development. Thousand Oaks, CA: Sage.

Bruner, J. S. (2005). Forward. In R. J. Sternberg \& D. D. Preiss (Eds.), Intelligence and technology: The impact of tools on the nature and development of human abilities (pp. ix-xi). Mahwah, NJ; Lawrence Erlbaum.

Burton, J. K., Moore, D. M., \& Magliaro, S. G. (2004). Behaviorism and instructional technology. In D. H. Jonassen (Ed.), Handbook of research on educational communications and technology ( $2^{\text {nd }}$ ed., pp. 3-36). Mahwah, NJ: Lawrence Erlbaum.

Chomsky, N. (2006). Language and mind ( $3^{\text {rd }}$ ed.). Cambridge, UK: Cambridge University Press.

Efendiogla, A., \& Yelken, T. Y. (2010). Programmed instruction versus meaningful learning theory in teaching basic structured query language (SQL) in computer lesson. Computers \& Education, 55, 1287-1299. doi: 10.1016/j.compedu.2010.05.026

Girvan, C., \& Savage, T. (2010). Identifying an appropriate pedagogy for virtual worlds: A communal constructivism case study. Computers \& Education, 55, 342-349.

Gordon, M. (2009). The misuses and effective uses of constructivist teaching. Teachers and Teaching: Theory and Practice, 15, 737-746.

Hill, W. F. (2002) Learning: A survey of psychological interpretation $\left(7^{\text {th }}\right.$ ed.), Boston, MA: Allyn and Bacon.

Huang, H. M., Rauch, U, \& Liaw, S. S. (2010). Investigating learners' attitudes toward virtual reality learning environments: Based on a constructivist approach. Computer \& Education, 55, 1171-1182 
Johnson, G. M. (2004). Constructivist remediation: Correction in context. International Journal of Special Education, 19, 72-88.

Johnson, G. M. (2007). College student Internet use: Convenience and amusement. Canadian Journal of Learning \& Technology 33, 141-157.

Johnson, G. M. (2008a). Cognitive processing differences between frequent and infrequent internet users. Computers in Human Behavior, 24, 2094-2106.

Johnson, G. M. (2008b). Functional internet literacy: Required cognitive skills with implications for instruction. In C. Lankshear \& M. Knobel (Eds.), Digital literacy: Concepts, policies and practices (pp. 33-46). New York: Peter Lang Publishing.

Johnson, G. M. (2008c). Verbal and visual reasoning in relation to patterns of Internet use. Internet Research, 18, 382-392.

Johnson, G. M. (2009). At-home internet behavior and cognitive development during middle childhood. Technology, Instruction, Cognition, and Learning, 6, 213-229.

Johnson, G. M. (2010). Internet use and child development: The techno-microsystem. Australian Journal of Educational and Developmental Psychology, 10, 32-43.

Johnson, G. M., \& Kupla, A. (2007). Dimensions of online behavior: Toward a user typology. CyberPsychology and Behavior, 10, 773-780.

Johnson, G. M., \& Puplampu, P. (2008). A conceptual framework for understanding the effect of the Internet on child development: The ecological techno-subsystem. Canadian Journal of Learning and Technology, 34, 19-28.

Kato, S., Kato, Y., \& Scott, D. (2009). Relationship between emotional states and emoticons in mobile phone email communication in Japan. International Journal on E-Learning, $8,358-401$. 
Kim, H. K., \& Bateman, B. (2010). Student participation patterns in online discussion: Incorporating constructivist discussion into online courses. International Journal of ELearning, 9, 79-98.

Kim, M. C., \& Hannafin, M. J. (2011). Scaffolding problem solving in technology-enhanced learning environments (TELEs): Bridging research and theory with practice. Computers \& Education, 56, 403-417. doi:10.1016/j.compedu.2010.08.024

King, A. B. (2008). Finding online subcultures in shared meaning. Social Science Computer Review, 26, 137-151.

Kirschner, P., Sweller, J., \& Clark, R. E (2006). Why minimal guidance during instruction does not work: An analysis of the failure of constructivist, discovery, problem-based, experiential, and inquiry-based teaching. Educational Psychologist, 41, 75-86.

Kotzee, B. (2010). Seven posers in the constructivist classroom. London Review of Education, 8, 177-187.

Kramarski, B., \& Michalsky, T. (2010). Preparing preservice teachers for self-regulated learning in the context of technological pedagogical content knowledge. Learning and Instruction, 20, 434-447.

Lam, P., Lam, S. L., Lam, J., \& McNaught, C. (2009). Usability and usefulness of eBooks on PPCs: How students' opinions vary over time. Australasian Journal of Educational Technology, 25, 30-44.

Luria, A. R. (1976). Cognitive development: Its cultural and social foundations. Cambridge MA: Harvard University Press.

Malikowski, S. R., Thompson, M. E., \& Theis, J. G. (2007). A model for research into course management systems: Bridging technology and learning theory. Journal of Educational Computing Research, 36, 149-173. 
Moats, L. (2007). Whole-language high jinks: How to tell when 'scientifically-based reading instruction' isn't. Washington, DC: Thomas B. Fordham Institute.

Moreno, R., \& Valdez, A. (2007). Immediate and delayed effects of using a classroom case exemplar in teacher education: The role of presentation format. Journal of Educational Psychology, 99, 194-206.

Nie, N. H., Simpser, A., Stepanikova, I., \& Zheng, L. (2005). Ten years after the birth of the Internet, how do Americans use the Internet in their daily lives? Stanford, CA: Stanford Center for the Quantitative Study of Society.

Neely, J. C., Blowers, K. W., \& Ragas, M. W. (2010). Virtual possibilities: A constructivist examination of educational application of Second Life. Journal of Interactive Learning Research, 21, 93-110.

Neo, M., \& Neo, T. K. (2010). Students' perceptions in developing a multimedia project within a constructivist learning environment: A Malaysian experience. Turkish Journal of Educational Technology, 9, 176-184.

Nickerson, R. S. (2005). Technology and cognitive amplification. In R. J. Sternberg \& D. D. Preiss (Eds.), Intelligence and technology: The impact of tools on the nature and development of human abilities (pp. 3-27). Mahwah, NJ: Lawrence Erlbaum.

Pennington, R. C. (2010). Computer-assisted instruction for teaching academic skills to students with autism spectrum disorders: A review of literature. Focus on Autism and Other Developmental Disabilities, 25, 234-248. doi: 10.1177/1088357610378291.

Piaget, J. (1970). The science of education and the pedagogy of the child. New York: Orion. Royer, J. (Ed.) (2005). The cognitive revolution in educational psychology. Greenwich, CT: Information Age Publishing.

Ruey, S. (2010). A case study of constructivist instructional strategies for adult online learning. British Journal of Educational Technology, 41, 706-720. 
Saine, N. L., Lerkkanen, M. K., Ahonen, T., Tolvanen, A., \& Lyytinen, H. (2010). Predicting word-level reading fluency outcomes in three contrastive groups: remedial and computer-assisted remedial reading intervention, and mainstream instruction. Learning and Individual Differences, 20, 402-414.

Schunk, D. H. (2004). Learning theories: An educational perspective $\left(4^{\text {th }}\right.$ ed.). Upper Saddle River, NJ: Merrill/Prentice Hall.

Scott, J. E., \& Walczak, S. (2009). Cognitive engagement with a multimedia ERP training tool: Assessing computer self-efficacy and technology acceptance. Information \& Management, 46, 221-232.

Sosa, G. W., Berger, D. E., Saw, A. T., \& Mary, J. C. (2011). Effectiveness of computerassisted instruction in statistics: A meta-analysis. Review of Educational Research, 81(1), 97-128. doi: 10.3102/0034654310378174

Soute, I., Markopoulos, P., \& Magielse, R. (2010). Head up Games: Combining the best of both worlds by merging traditional and digital play. Personal and Ubiquitous Computing, 14, 435-444.

Steinkuehler, C. (2009). Video games and digital literacies. Journal of Adolescent \& Adult Literacy; 54, 61-63. doi:10.1598/JAAL.54.1.7

Suh, J. (2010). Leveraging cognitive technology tools to expand opportunities for critical thinking in elementary mathematics. Journal of Computers in Mathematics and Science Teaching, 29, 289-302.

Tekos, G., \& Solomonidou, C. (2009). Constructivist learning and teaching of optics concepts using ICT in Greek primary school: A pilot study. Journal of Science Education and Technology, 18, 415-428 
Torraco, R. J. (2002). Cognitive demands of new technologies and the implications for learning theory. Human Resource and Development Review, 1, 439-467. Doi: $10.1177 / 1534484302238436$

Vance, D. E., McNees, P., \& Meneses, K., (2009). Technology, cognitive remediation, and nursing directions for successful cognitive aging. Journal of Gerontological Nursing 35, 50-56.

Vogel-Walcutt, J. J., Gebrim, J. B.,Bowers, C., Carper, T. M., \& Nicholson, D. (2011). Cognitive load theory vs. constructivist approaches: Which best leads to efficient, deep learning? Journal of Computer-Assisted Learning. 27(2), 133-145. doi:10.1111/j.13652729.2010.00381.x

Vygotsky, L. S. (1978). Mind in society: The development of higher mental process. Cambridge, MA: Harvard University Press.

Warren, L., \& Fuller, T. (2010). Capturing the dynamics of co-production and collaboration in the digital economy. Leonardo, 43, 200-201.

White, B. Y., Collins, A. \& Frederiksen, J. R. (2011). The nature of scientific metaknowledge. In M. S. Khine \& I. Saleh (Eds.), Dynamic modeling: Cognitive tool for scientific enquiry (pp. 41-76). London: Springer. Zaidel, M., \& Luo, X. H. (2010). Effectiveness of multimedia elements in computer supported instruction: Analysis of personalization effects, students' performances and costs Journal of College Teaching \& Learning, 7, 11-16.

Zhang, X., Olfman, L., \& Firpo, D. (2010). Supporting social constructivist learning through the KEEP SLS ePortfolio System. International Journal of E-learning, 9, 411-426. 
Figure 1.

An Ecological Model of Interactive Learning Environments

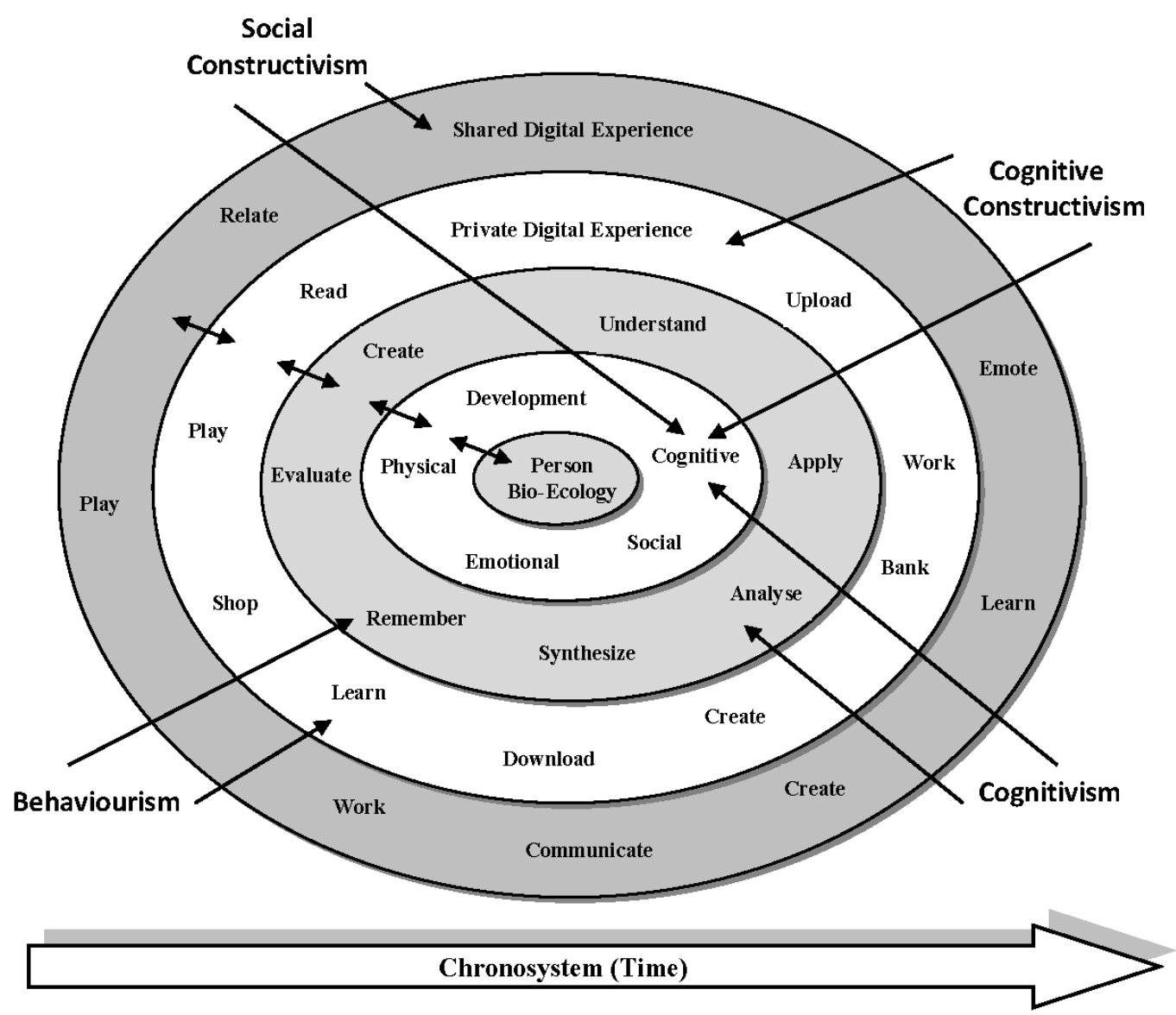

